\section{COVID Vaccine and Privilege: When Is It Not About You? \\ Joshua Freeman, MD}

Originally published in the Medicine and Social Justice blog, https://medicinesocialjustice.blogspot.com/2021/02/covidvaccine-and-privilege-when-is-it.html

Recently, an article from CNN, "A vaccination site meant to serve a hard-hit Latino neighborhood in New York instead serviced more Whites from other areas”, was posted on a medical social justice page of which I am a member. Among a number of others, I expressed my displeasure at this, but I also posted a comment in which I unfortunately said "People are scum". It did not specifically refer to the white people who had obtained these vaccines, perhaps inappropriately, but certainly could be seen as that. I was called out for that comment, and that was appropriate. People are not scum, for better and worse. Scum is a substance that exists without intentionality. People, however, do have intentionality, and that can make them do things that are very good and very bad and everything in between. Certainly, doing something bad, or wrong, does not make a person bad; many religions have doctrines that are more or less comparable to "hate the sin, love the sinner".

More to the point is whether the people referred to in the article did anything wrong or objectionable at all. While those quoted in the article were very critical of this behavior, some of those posting comments on the page felt that these people (presumably people who otherwise met the current criteria in NY for the vaccine, by age or health status) were just trying to do what they could, and not trying to use their privilege to obtain vaccine intended for the minority community. They agreed that the system, and the structure for distributing the vaccine was severely flawed and probably inequitable, but that the individuals pursuing the vaccine should not be condemned. They acknowledged that some people, by virtue of education, wealth, computersavvy, connections to other family members who may be more computer-savvy, and other characteristics, are more able to avail themselves of benefits. Even when this results in preferentially vaccinating white people rather than the minorities for whom it was intended (by placing vaccination sites in minority communities), it does not mean those individuals (many of whom are sick and elderly) are doing a bad thing, still less are bad people, or certainly scum. Nonetheless, the result is the result; the New York Times on
January 31, 2021 reports that "Data showed that while 24\% of city residents are Black, only $11 \%$ of vaccine recipients were. White New Yorkers received a disproportionate share of the shots.

The CNN report was not the only one critical of people “jumping the queue”. In a NY Times Op-Ed on January 28, 2021, Elisabeth Rosenthal MD, editor of Kaiser Health News, writes "Yes, It Matters That People Are Jumping the Vaccine Line":

For weeks Americans have watched those who are well connected, wealthy or crafty "jump the line" to get a vaccine, while others are stuck, endlessly waiting on hold to get an appointment, watching sign-up websites crash or loitering outside clinics in the often-futile hope of getting a shot.

She adds, agreeing with some of the points made by the commenters on the site, "I don't blame the lucky recipients; after all, hospitals would just offer the unused vaccine to the next person on the list," but also notes that "The problem is that often, people are not really being "offered" the vaccine; in some cases, they are grabbing it through position, influence or deceit.” How often? I don't know, and probably Rosenthal does not either. Or, for that matter, those who posted comments on the page, although they seem to be from NY and likely to know a lot more about the situation there than I do.

Most likely, the predominantly white recipients of the vaccine being offered in minority neighborhood represent a spectrum of people. They would include those who consciously believe that they are special and privileged and deserve to be at the head of the line, those who believe in equity but let that concern be overcome by their selfinterest, and those who are appropriately candidates for the vaccine in the current phase but are desperate, confused, and, with no negative or ignoble intent, found their way to that place and time. Defending the latter, however, does not excuse the former, and there are certainly many of them. Freeman's Law (which I should probably rename "Freeman's First Law" so as not to confuse it with Freeman's Second Law, to which I referred in my blog post of January 28, 2021, "Vitamin D, false nostrums, and conspiracy theories: The world has enough real problems,") states that in any program designed to help a group of people, no matter how narrowly defined, those with the relatively least need are most likely to benefit. Thus in a program designed, say, to help homeless pregnant teenagers with HIV living under bridges, those who have some greater resources (a bit more education, a slightly less traumatic childhood, etc.) will be the ones who are able to access it first. The larger 
the universe of people who are targeted, the more people who would qualify for services, the greater the disparity is likely to be. This is of course especially true in the case of COVID vaccine, where the target population is, ultimately, everyone.

Another aspect of the comments posted that was interesting to me was that they referred to those seeking to get the vaccine as "patients". Perhaps this is understandable on a medical site, and it is quite possible that some of those involved were patients of those doctors who made the comments. I have sometimes been critical of the use of the term "patients", noting that it was the "medical" word for what in English are called "people”, and that it could tend to diminish their humanity. I am quite sure this was not the intent of those using it, but in this context it has quite another flaw. Calling folks "patients", especially when they are not your patients, carries a connotation of dependency, needing help from their doctor. Calling them "people" implies more that they have agency, the ability to make decisions, prioritize needs and values, and act on them. While it is often true that many people, particularly the sickest and oldest and least educated and least empowered do need help, it is also true that when the affected universe is the entire population, it includes all of us, all people, adults and children, young and old, Black and White, rich and poor, doctors and "patients". It includes those who are the wealthiest, most educated, most connected, and most empowered, who are often find ways to get to the head of the line. Thus, prioritizing who should get the vaccine first and enforcing that is critical. Social justice is about promoting equity, which means giving more help to those who have the least and need it the most, and reducing the temptation to give in to those whose privilege or loud voice is most demanding.

Rosenthal writes:

The United States has allowed its public health system to become a hollowed-out underfunded mess, and many vaccination clinics are being run and staffed by contracted private companies. And the private sector has so far proved too vulnerable to private favoritism.

Until the supply is sufficient, the government needs to give the shots to the people and places that need it most, and find ways to ensure that the plan is followed; the system could prioritize ZIP codes that have high Covid-19 infection rates or target low-income populations who might otherwise have a difficult time securing an appointment.

She is absolutely correct, but clearly targeting certain ZIP codes is not sufficient, as the Times describes on February 2, 2021 in 'Even in Poorer Neighborhoods, the Wealthy Are Lining Up for Vaccines' (Feb 3 print title: 'Where poor suffer most, wealthy find vaccines'). And a 52-year old celebrity on-line fitness trainer got the vaccine as an 'educator'. Meanwhile the COVID surge most hurts those in the poorest neighborhoods, as in LA. And people behaving as though the doors were opening at a department store the day after Thanksgiving is not just a NY problem. a friend in another city, on seeing the pushing and shoving, both literal and figurative, that went on when they went to get their vaccine, said "I wouldn't want to be in a concentration camp with those people."

The problem, if you think it is a problem, of empowered people going to poor neighborhood to get their vaccines is real and ongoing. I think that folks who do so are doing a selfish thing, a bad thing. This in itself does not make them bad people, or certainly scum. However, for the record, I personally believe that there are indeed bad people, and that doing enough bad things often enough, predictably enough, and bad enough does make someone a bad person (see, e.g.,"Nazis").

We should have compassion for those with need, and the most compassion for the greatest need. And recognize that "me" is not the hallmark of social justice. 